\title{
LA POLÉMICA SOBRE ACENTUACIÓN ORTOGRÁFICA ENTRE CARLOS MARTÍNEZ VIGIL Y FIDELIS DEL SOLAR
}

\section{THE DEBATE ABOUT ORTHOGRAPHIC ACCENTUATION BETWEEN CARLOS MARTÍNEZ VIGIL AND FIDELIS DEL SOLAR}

\author{
Mariela Oroño \\ Universidad de la República (Uruguay) \\ marielaor@adinet.com.uy
}

Resumen:

En este trabajo estudio la polémica sobre acentuación ortográfica mantenida entre el uruguayo Carlos Martínez Vigil y el chileno Fidelis Del Solar entre mayo de 1896 y febrero de 1897 en la Revista Nacional de Literatura y Ciencias Sociales de Uruguay a lo largo de seis cartas publicadas en la revista. Del Solar defendía la "ortografía chilena" y Martínez Vigil la "ortografía académica". A partir de estas posiciones iniciaron un debate linguísticoideológico que muestra dos posiciones diferentes entre los intelectuales americanos de la época respecto de la independencia cultural y lingüística de los países hispanohablantes en relación con España que ponía en juego la valoración de la unidad linguiística de estas naciones. La polémica también da cuenta de que más allá de las normas que cada uno defendía, ambos estudiosos compartían una concepción ilustrada de la ortografía, que debía alcanzar el ideal de sencillez, racionalidad y utilidad.

Palabras clave: acentuación ortográfica, polémica, Fidelis del Solar, Carlos Martínez Vigil, siglo XIX. 
Abstract:

This paper studies the debate over orthographic accentuation maintained by Uruguayan Carlos Martinez. Vigil and the Chilean Fidelis Del Solar between May 1896 and February 1897 in the Revista Nacional de Literatura y Ciencias Sociales of Uruguay on six letters published in the journal. Del Solar defended the "Chilean orthography" and Martinez Vigil the "Academic orthography". From these positions began a linguistic ideological debate showing two concurrent positions among Hispanoamerican intellectuals of the time regarding the linguistic independence of Spanish-speaking countries in relation to Spain. The controversy also shows that beyond the norms that defended, they shared an Enlightenment conception of orthography and the ideal of simplicity, rationality and usefulness of it.

Keywords: orthographic accentuation, debate, Fidelis del Solar, Carlos Martinez Vigil, nineteenth century.

\section{Introducción}

En este trabajo estudio la polémica sobre acentuación ortográfica mantenida entre el filólogo uruguayo Carlos Martínez Vigil y su colega chileno Fidelis Del Solar entre mayo de 1896 y febrero de 1897 en la Revista Nacional de Literatura y Ciencias Sociales (RNLCS) de Uruguay.

El debate da cuenta de dos posiciones políticolingüísticas de fines del siglo XIX en Hispanoamérica en relación con la ortografía castellana: la "ortografía chilena", defendida por Del Solar, y la "ortografía académica", defendida por Martínez Vigil. Como todo debate ideológico sobre el lenguaje "forma parte de procesos socio-políticos más generales" (Blommaert 2). Las dos normativas ortográficas a las que se alude reflejan una preocupación 
recurrente en la época, como resultado de la independencia de los países americanos en relación con España, y los problemas que eso planteaba en todos los dominios, incluyendo el linguiístico. La polémica por otra parte se centra en un aspecto que no ha sido objeto central de estudios sobre la temática como es las divergencias entre ambas propuestas ortográficas en cuanto a la tildación de palabras.

Estimo que el análisis permitirá aportar al conocimiento acerca de las representaciones sobre la ortografía del español que primaba en los dos países hispanos involucrados: Chile, con una gran tradición independentista en términos lingüísticos, y Uruguay, más apegado a las recomendaciones académicas. Se trata de un tema que relaciona el estudio de las políticas lingüísticas con las representaciones sobre el lenguaje. Las políticas lingüísticas implican decisiones conscientes, planificadas, sobre el uso público del lenguaje tomadas fundamentalmente por los Estados, porque son quienes cuentan con los recursos económicos y el poder político para imponer las decisiones adoptadas (Jernudd y Das Gupta 198, Calvet 5). En estas decisiones participan las representaciones sobre el lenguaje, en tanto esquemas mentales socialmente compartidos sobre las lenguas, y que por lo tanto condicionan la percepción y evaluación de los fenómenos lingüísticos y de quienes los usan (Jodelet 474, Boyer 13, Narvaja de Arnoux y Del Valle $3)$.

Esta polémica por otra parte ilustra la importancia de la prensa como plataforma de discusión en el siglo XIX y el diálogo existente entre los intelectuales hispanoamericanos, en este caso particular, uruguayos y chilenos. Los artículos aparecidos en la RNLCS son cartas personales cuyos autores las hicieron públicas. Este interés en volver público un intercambio privado da cuenta de que en el siglo XIX la prensa se volvió un espacio privilegiado para la divulgación 
de temas que se estimaba interesante dar a conocer. La prensa era el instrumento que acercaba la palabra del intelectual a su público (Halperin Donghi 334). Por ello, la difusión del intercambio epistolar con un intelectual de mayor renombre le sirvió además a Martínez Vigil para hacerse conocer; le permitió reforzar su imagen como intelectual. El estudio de la polémica muestra también las inquietudes lingüísticas compartidas por los intelectuales hispanoamericanos más allá de su país de origen.

\section{La plataforma de discusión: la Revista Nacional de Literatura y Ciencias Sociales}

La Revista Nacional de Literatura y Ciencias Sociales (RNLCS) fue una publicación bimensual que se editó en Montevideo (Uruguay) durante casi tres años. Su primer número apareció el 5 de marzo de 1895 y el último el 25 de noviembre de 1897. Se publicaron en total 60 números. Cada entrega tenía 16 páginas de gran formato, impresas a tres columnas.

Sus directores eran, en el orden de presentación en la portada, Daniel Martínez Vigil, Víctor Pérez Petit, Carlos Martínez Vigil y José Enrique Rodó. Todos ellos, muy jóvenes entonces, serían luego personalidades del ámbito intelectual uruguayo, algunas incluso muy destacadas como es el caso de Rodó. En la RNLCS los hermanos Daniel y Carlos Martínez Vigil se dedicaron fundamentalmente a la poesía el primero y a los estudios sobre el lenguaje el segundo. Pérez Petit y Rodó se centraron en la crítica literaria y en la escritura de ensayos sobre diversas temáticas. Pérez Petit, el único que entonces tenía notoriedad como literato, también cultivó en estas páginas diversos géneros literarios. Los cuatro redactores debatían sobre temas relacionados con las letras, la lengua, el arte, la filosofía, la sociología y el derecho, sin decantarse por una corriente filosófica o literaria 
particular. En sus páginas se observan las fuertes vinculaciones con otros escritores nacionales y extranjeros, mediante cartas, noticias y reseñas sobre libros y revistas procedentes de España y de varios países hispanoamericanos. Estas colaboraciones también muestran el eclecticismo literario y filosófico de la revista, dando lugar muchas veces a disputas entre sus autores, como la que nos ocupa en este trabajo ${ }^{1}$.

La RNLCS se convirtió rápidamente en un referente dentro de la intelectualidad nacional e hispanoamericana. Montero Bustamante señala al respecto que:

Los escritores del país y de América, y el público en general, se interesaron vivamente por el nuevo cenáculo literario que había surgido en Montevideo, y siguieron con viva curiosidad la aparición de los números sucesivos de la

1 En el primer número, por ejemplo, colaboraron los uruguayos Manuel Bernárdez, Orestes Araújo, Elías Regules, Luis D. Desteffanis, Víctor Arreguine, José P. Massera, José Espalter, Eduardo Ferreira, Tomás Claramunt, Francisco Pissano y María Eugenia Vaz Ferreira. En números posteriores participaron los ya reconocidos Juan Zorrilla de San Martín, Carlos Roxlo y Eduardo Acevedo Díaz (Pérez Petit 55). Del extranjero escribieron en la revista figuras de varios países de América, lo que permitió estrechar vínculos con los centros más importantes del continente: Santiago de Chile y Buenos Aires, Lima y Caracas, Colombia y Ecuador; también hubo escritores españoles. Entre los que enviaron poesías, novelas, estudios filológicos o cartas, se encuentran Leopoldo Alas (Clarín), Ricardo Palma, Enrique Gómez Carrillo, Eduardo de la Barra, José Pardo, Mariano José Madueño, Adolfo Valderrama, Rubén Darío, Eduardo de la Barra, Leopoldo Lugones, Rafael Merchán, Bartolomé Mitre, Santos Chocano, Francisco García Cisneros, Isaías Gamboa, Rafael Obligado, Fidelis del Solar, Salvador Rueda, Rufino Blanco Fombona, Soto y Calvo, Carlos Alfredo Becú, Carlos María de Pena, Joaquín de Salterain, Miguel Luis Amunátegui Reyes, Salvador Rueda, Carlos Gagini, Tomás Guevara y Ernesto Quesada. Este intercambio también dio a conocer la intelectualidad uruguaya en el extranjero. 
revista, al extremo que este hecho constituía un acontecimiento que despertaba verdadera expectativa, especialmente entre los adolescentes y jóvenes, que consideraban aquel cenáculo como un verdadero Olimpo (26).

Y agrega que

Por su valor intrínseco, por la jerarquía intelectual de sus directores, por la inquietud espiritual que provocó la revista en el medio ambiente, por la acción docente que ejerció y por la influencia que logró, puede compararse con El Iniciador, el periódico fundado en 1838 en Montevideo por Andrés Lamas y Miguel Cané, que fue realmente el iniciador del Romanticismo en el Río de la Plata (Montero Bustamante 21).

Como antes en El Iniciador, a fines del siglo XIX en la RNLCS “Toda el alma de una generación estaba allí; toda su fe, todo su ensueño, toda su vida espiritual" (Pérez Petit 45). Según se indica en el primer número de la RNLCS, este era precisamente el fin que buscaban sus directores:

Dejábase sentir desde algún tiempo acá la necesidad de una revista que reflejara con exactitud la vida cerebral de las nuevas generaciones; que fuera su expresión genuina en cuanto atañe a los levantados ideales que persigue en materia científica y literaria, y que no tuviese atingencia con el carácter distintivo de las hojas diarias de publicidad, las cuales, por el propio ministerio para que han sido fundadas, prestan más atención al tejemaneje de la política y a las informaciones del noticierismo sensacional, que a los trabajos de la abstrusa ciencia o de las letras humanas (año 1, n ${ }^{\circ} .1,5$ de marzo de 1895). 
A pesar del prestigio y difusión que había logrado, la RNLCS dejó de publicarse casi tres años después de haber salido a luz el primer número. Como recordara años más tarde Pérez Petit (108), "La guerra que había azotado al país durante el año 1897, contra el Presidente Idiarte Borda, la fatiga mental que tres años de esfuerzos y preocupaciones continuos nos había propiciado; la necesidad de ejercitar nuestra acción en otro terreno, otras más pequeñas causas aún nos condujeron a hacer cesar la Revista Nacional”.

\section{Los protagonistas: Carlos Martínez Vigil y Fidelis del Solar}

Cuando Carlos Martínez Vigil (1870-1949) cofundó la RNLCS era un joven estudiante de la carrera de derecho. Ya con el título de doctor, siguió conjugando este trabajo con sus inquietudes sobre el lenguaje. Fue docente de Gramática Castellana en la Universidad de Montevideo (única universidad del país, antecedente de la Universidad de la República) y fundador de la Academia Nacional de Letras, ${ }^{2}$ de la que fue su vicepresidente. Entre sus obras sobre temas lingüísticos se destacan Ligeras nociones de acentuación

2 El interés de Carlos Martínez Vigil en crear una academia de la lengua data de la época en que cofundó la RNLCS. Sobre esta inquietud, compartida con otros intelectuales, Pérez Petit recuerda que "Conversando, precisamente, con Daniel y Carlos Martínez Vigil, con Félix Bayley y con Eduardo Pueyo [...], surgió entre ellos la idea de fundar una Academia Nacional, cuyo fin, semejante al de la Española, sería velar por el lenguaje. El propósito, que provocó largos e interesantes debates entre los entusiastas y soñadores contertulios, se llevó hasta redactar un acta de fundación, que suscribieron aquellos, y algunos otros pocos muchachos, que hallaron momentáneamente en esa gestión un derivativo de sus ansias de trabajar, de hacer algo...Por lo demás, la idea no fue más adelante; más ello se debió a que los incipientes académicos descubrieron ser más práctico fundar una revista literaria que reunirse en cónclave para vigilar la limpieza y esplendor del idioma" (49). 
ortográfica (1889), Sobre lenguaje (1897) y Arcaísmos españoles usados en América (1939). Colaboró regularmente en el Boletín de Filología. A pesar de su labor filológica y a diferencia de otras figuras uruguayas de fines del siglo XIX (probablemente por su propio perfil, alejado de las funciones de gestión política, cultural o educativa; cfr. Oroño), Martínez Vigil no adquirió particular relevancia pública en Uruguay más allá del ámbito académico.

Fidelis del Solar (1836-1910) tuvo un rol destacado en el desarrollo de la lingüística en Chile (Rojas y Avilés 1, Figueroa 276- 277), y también ocupó un lugar importante debido a sus estudios musicales. En la época que nos ocupa ya era una figura de relevancia en Hispanoamérica por sus trabajos sobre el lenguaje (Figueroa 276- 277), sobre todo lexicológicos, entre los que se destacan Reparos al "Diccionario de chilenismos" del señor don Zorobabel Rodriguez (1870), Estudios filolójicos (1885), Vocabulario de la fraseología del verbo 'echar' (1889), Voces usadas en Chile. Juicio crítico de la obra que con este título acaba de dar a luz don Aníbal Echeverría y Reyes (1900). Colaboró activamente en La Linterna Literaria, La Revista Ilustrada, El Correo Literario, La República, Los Tiempos, La Lei, El Mercurio, La Libertad Electoral y los Anales de la Universidad de Chile (Figueroa 277).

\section{La polémica}

\subsection{El origen del debate}

El 14 de abril de 1896 Martínez Vigil le escribió una carta a su colega chileno para invitarlo a colaborar con un artículo en la RNLCS para "estrechar los vínculos de la fraternidad americana" (Del Solar 8). Del Solar aceptó la invitación y envió la traducción de un capítulo de Jan Blas ("Sobre el capítulo $6^{\circ}$. de Jil Blas de Santillana "Una omision 
del Padre Isla"3) acompañada de una carta solicitando que para su difusión se respetara la ortografía original. También adjuntó tres trabajos suyos para su difusión en el medio uruguayo (los ya citados Reparos al Diccionarios de chilenismos del señor don Zorobabel Rodriguez, Estudios filolójicos y Vocabulario de la fraseología del verbo 'echar'). En la mencionada carta (publicada también en la RNLCS) Del Solar defendía la ortografía chilena y censuraba fuertemente la ortografía académica. Este cuestionamiento fue el disparador de la polémica sobre acentuación ortográfica entre él y Martínez Vigil. Del Solar dio por terminado el debate, en su última carta: "doi por terminada nuestra elevada i tranquila polémica, i concluyo respetando, como siempre, su modo de pensar". Martínez Vigil respondió a su vez y de este modo se concluyó el intercambio epistolar sobre el tema ${ }^{4}$.

La discusión se desarrolló entre mayo de 1896 y febrero de 1897 con el intercambio de seis cartas (salvo la primera, muy extensas); tres escritas por Del Solar y tres por Martínez Vigil ${ }^{5}$. A continuación indico las fechas de cada carta, su autoría y el número de la revista en la que fue publicada. Entre corchetes señalo el modo en que haré referencia a cada una a partir de ahora:

- Carta 1. Autor: Fidelis del Solar. Fecha: 2 de mayo de 1896. RNLCS, $n^{\circ} .28$ (25 de mayo de 1896). [DS1]

3 Respeto la ortografía del original en todos los casos.

${ }^{4}$ El 14 de enero de 1898, Del Solar volvió a escribir una carta que no llegó a su destinatario, Martínez Vigil, porque la RNLCS ya había cerrado. Esta carta fue finalmente publicada el mismo año con el título "Carta abierta de par en par" en el anexo dominical de La lei (en los números 7 a 14), de Chile. Esta separata publicada como libro fue enviada oportunamente por su autor a Martínez Vigil.

${ }^{5}$ En 1941 Martínez Vigil publicó partes de estas cartas en su libro Polémica sobre acentuación ortográfica. 
- Carta 2. Autor: Carlos Martínez Vigil. Fecha: 12 de junio de 1896. RNLCS, no 29 (10 de junio de 1896). [MV1).

- Carta 3. Autor: Fidelis del Solar. Fecha: 7 de julio de 1896. RNLCS, $n^{\circ} .32$ (25 de julio de 1896). [DS2].

- Carta 4. Autor: Carlos Martínez Vigil. Fecha: 25 de agosto de 1896. RNLCS, n ${ }^{\circ} .34$ (25 de agosto de 1896).[MV2].

- Carta 5. Autor: Fidelis del Solar. Fecha: 14 de setiembre de 1896. RNLCS, $n^{\circ} .38$ (25 de octubre de 1896). [DS3].

- Carta 6. Autor: Carlos Martínez Vigil. Fecha: 25 de febrero de 1897. RNLCS, $\mathrm{n}^{\circ}$. 46 (25 de mayo de 1897). [MV3].

Las dos propuestas ortográficas sobre las que se centraba la discusión eran la "ortografía reformada que usamos en Chile siguiendo a Don Andrés Bello" (DS1) u "ortografía chilena" (DS1) por un lado, y la "ortografía española" (DS1), "ortografía académica" (DS1), "reforma académica" (MV1) o "reforma de 1883" (MV1, DS1 y 2) por otro. La primera expresión aludía a lo que se conoce como “ortografía chilena”, y que como el propio Del Solar señalaba no era la reforma propuesta por Bello $^{6}$, aunque estaba

6 En 1842 se fundó la Universidad de Chile, con el destacado filólogo y gramático venezolano Andrés Bello como rector y el futuro presidente argentino Domingo Faustino Sarmiento como miembro fundador. Una de las tareas de la institución era supervisar la educación elemental. Sarmiento, animado por el propio Bello, presentó en 1843 su Memoria sobre ortografía americana, en la que proponía una serie de reformas ortográficas basadas en las propuestas en 1823 por Bello y García del Río en Indicaciones sobre la conveniencia de simplificar y uniformar la ortografía en América. Aunque ambas reformas proponían un sistema ortográfico basado en la pronunciación (descartando los criterios de etimología y uso, que eran los que primaban en la ortografía académica de 1844), la propuesta de Sarmiento era más extrema, al reclamar una ortografía que se basara estrictamente en la pronunciación americana. La 
inspirada en ella. A propósito, Rosenblat (CXXII) propone diferenciar entre "ortografía reformada", "ortografía chilena" y "ortografía de Bello":

La 'ortografía reformada' era la adoptada en su reforma de 1844 por la Facultad de Filosofía y Humanidades (ombre, qeso, oi, onrra, jente), siguiendo las ideas de Bello, y que duró dos o tres años; la 'ortografía chilena' es lo que persistió en Chile de esa reforma, es decir, tres rasgos (rei, jente, estraño); la 'ortografía de Bello, o la que aplicó después del fracaso de la reforma, [...] se reducía a los dos rasgos de empleo uniforme y regular de $j$ e $i$.

En su primera comunicación con Martínez Vigil, Del Solar indicaba los rasgos característicos de la "ortografía chilena", que pedía que se respetaran en su publicación. También señalaba que en su trabajo seguía la normativa adoptada por el Consejo de Instrucción Pública de Chile, "por decreto de 30 de julio del año último [1895]", respetando la "práctica seguida hace ya medio siglo por los chilenos". Decía Del Solar: "Sensible seria para nosotros volver a considerar como vocal, en ciertos casos, a la $y$, a la $g$ dándole sonido de $j$ i a la pedante $x$ cuando entra en composición antes de consonante" (DS1).

iniciativa de Sarmiento fue puesta a consideración por un comité nombrado por Bello y no fue apoyada. La propuesta finalmente aprobada en 1844 era muy similar a la elaborada por Bello en 1823 (Martínez de Sousa 621, 633- 635, Arnoux 168-176). Tanto las iniciativas de Bello y de Sarmiento como la reforma efectivamente llevada a la práctica en Chile en 1844 y las polémicas derivadas de las tres propuestas han sido profusamente estudiadas (cfr. por ejemplo Arnoux; Niño- Murcia; Área, Pérez y Rogieri; Martínez de Sousa). 
La "ortografía chilena”, en lo que a grafías se refería, proponía sustituir $y$ por $i$ cuando aquella tenía valor vocálico, sustituir $g$ por $\mathrm{j}$ cuando se correspondía con el fonema / $\mathrm{x} / \mathrm{y}$ eliminar la $x$ en favor de la $s$ cuando estaba antes de consonante. Los ejemplos que ofrece Rosenblat resumen las medidas adoptadas: "rei, jente, estraño" (CXXII) ${ }^{7}$. Del Solar reconocía que esta ortografía era un paso "para llegar al fonetismo mas tarde" (DS1).

La normativa ortográfica que Del Solar llamó “ortografía española" u "ortografía académica", y Martínez Vigil, "reforma académica" o "reforma de 1883" (expresiones estas últimas que Del Solar recogió en sus respuestas a Martínez Vigil) eran las modificaciones ortográficas realizadas por la Real Academia Española en la decimosexta edición de la Gramática de la lengua castellana, de $1883^{8}$. Del Solar, fiel a la ortografía chilena, opinaba que la reforma ortográfica de 1883 era "desatinada" y "rancia" (DS1); "pródiga en acentos i amiga de dar oficios dobles a las letras" (DS1), con reglas "engorrosas y de caprichos sin cuento" (DS1).

Martínez Vigil en cambio consideraba que Del Solar, al preferir la norma chilena, estaba "apegado a lo antiguo,

7 La "ortografía chilena" se conservó en Chile hasta 1927, cuando se suprimió por un decreto presidencial que estableció que se adoptara la ortografía académica en todos los documentos públicos y en las escuelas (Arnoux 175- 176).

${ }^{8}$ En cuanto al contenido, esta edición era prácticamente igual a la anterior, de 1880 (Gómez Asencio 36, 40). Según estudia Gómez Asencio, aunque la RAE realizó reimpresiones y nuevas ediciones de su Gramática (13 en total), en cuanto al contenido no hubo cambios desde 1880 hasta el texto de 1917 (36). Dentro del contenido se dedica aproximadamente un 14 \% a ortografía (Gómez Asencio 45). Desde 1870 y hasta 1916 la RAE eliminó toda referencia que no fuera ella misma como autoridad respecto a los modelos de corrección lingüística (Gómez Asencio 49). 
demasiado condescendiente con el uso" (MV1), y que la reforma académica era "más filosófica y matemática que la práctica chilena, menos sujeta a dudas y vacilaciones, y más de acuerdo con los principios de la razón y de la lógica" (MV1).

A partir de estas posiciones se inició un debate linguiístico-ideológico entre las dos figuras, que muestra, más allá del contenido ortográfico en discusión, dos posiciones coexistentes entre los intelectuales americanos de la época respecto de la independencia cultural y lingüística de los países hispanohablantes en relación con España que ponía en juego la valoración de la unidad lingüística de estas naciones. La polémica también da cuenta de que más allá de las normas ortográficas que cada autor defendía, ambos compartían una concepción ilustrada de la ortografía que, entendían, podía y debía ser perfeccionada para alcanzar el ideal de sencillez, racionalidad y utilidad, tres pilares de la modernidad (Arnoux 188), como aparece ya esbozado en las palabras de Martínez Vigil y Del Solar recién citadas.

\subsection{El contenido de la polémica}

El debate entre Del Solar y Martínez Vigil no se centra, como podría esperarse, en las diferencias grafemáticas entre la ortografía chilena y la académica, sino en las discrepancias en cuanto a la tildación de las palabras. Recordemos que la acentuación había sido ya objeto de preocupación para Martínez Vigil (su libro Ligeras nociones sobre acentuación ortográfica es de 1889).

Discutieron sobre el uso del tilde en la preposición $a$, y las conjunciones $e, i$ y $o$; en los patronímicos; sobre los tildes "diferenciales"; en hiatos y en palabras agudas, graves y esdrújulas. El centro de la cuestión estuvo en las diferencias normativas para acentuar las palabras agudas y graves terminadas en $n$ y $s$. Antes de centrarme en este aspecto, 
resumo brevemente la discusión sobre los fenómenos antes señalados.

Sobre el tilde en la preposición $a$, y las conjunciones $e, i$ y $o$, Martínez Vigil recordaba que no se tildaban en ninguna de las dos propuestas ortográficas; aunque reconocía que de todas formas se tildaban en la tradición académica, señalaba que se trataba de "una costumbre que desaparecerá sin duda antes de mucho, por carecer de fundamento en que apoyarse" (MV3).

En cuanto a la tildación de los patronímicos, había diferencias de criterio. Mientras que en la ortografía chilena se tildaban si llevaba tilde el nombre del que derivaban, en la ortografía académica seguían las reglas generales de acentuación. Para Martínez Vigil la norma chilena atentaba contra la fijeza, la invariabilidad y sencillez de las reglas ortográficas:

La fijeza del sistema que Vd. defiende es, como fijeza, de la clase peor que conozco. Porque ¿qué decir de un sistema de acentuación que ordena no marcar el signo gráfico en los patronímicos en z, como González, Martínez, sino cuando el nombre propio de que se derivan se acentúa como Álvarez? ¿Es decir que Álvarez, esdrújulo, dejaría de acentuarse si fuera derivado de Alvaro, en vez de Álvaro, o de Alvar, como se decía en lo antiguo? ¿Qué es entonces de la invariabilidad y fijeza de las reglas seguidas en Chile en materia de acentuación ortográfica? Aun suponiendo que el público, que por lo común no repara en estas distinciones, fuera capaz de observarlas prácticamente, siempre sería preferible la doctrina que prescinde de ellas por innecesarias y que subordina estos casos a las reglas de aplicación 
general que ha establecido. [...]. "Vd. mismo canta la palinodia en sus "Estudios", y después de escribir Fernandez, Vargas, Flores, Suarez, agrega: "Queda solamente la acentuación divergente de los patronímicos: acentúense todos y las dificultades habrán desaparecido por completo? (MV3)

Sobre los "acentos diferenciales" ambos sistemas estaban de acuerdo, aunque Martínez Vigil identificaba una diferencia en la escritura de aun. La ortografía chilena no acentuaba aún, según Del Solar siguiendo "la práctica chilena y de la mayor parte de los que hablan castellano" (DS2). La ortografía académica proponía escribir "aun cuando precede a verbo, aún cuando lo subsigue” (MV3).

Por último, ambos autores encontraban dificultad en la tildación de diptongos crecientes, donde ocurría "el encuentro de una vocal débil [cerrada] seguida de una llena [abierta] cuando no forman diptongo" [hiato], caso "que sí ofrece verdadera dificultad i en lo que existe variedad de opiniones" (DS3). Sobre este punto ambos autores estaban en desacuerdo con la ortografía académica.

\subsection{El centro del debate: la tildación de voces graves y agudas terminadas en $n$ y $s$}

Sobre la tildación de las voces agudas, graves y esdrújulas vale recordar, siguiendo a Martínez Vigil, que antes de la reforma académica de 1883 las reglas de acentuación de las palabras establecían diferencias según fueran "plurales o voces compuestas, de si las simples de que se deriven, o los singulares de que forman, llevan marcado o no el signo acentual, y de si son sustantivos, pronombres o verbos" (MV1). La "moderna ortografía", en cambio, "acentúa las palabras según principios de aplicación general", 
esto es, según las palabras sean agudas, graves y esdrújulas (MV1).

La propuesta académica de 1883 en cuanto a tildación podía resumirse, según Martínez Vigil,

en tres principios: $1^{\circ}$. Las dicciones terminadas en vocal, ó en las consonantes $n, s$, no se acentúan cuando la pronunciación carga en la penúltima sílaba, y se acentúan cuando carga en otra cualquiera [se acentúan cuando son agudas]; $2^{\circ}$. las dicciones terminadas en consonante, excepto $n$ o $s$, no llevan acento cuando la pronunciación carga en la última sílaba, y se acentúan cuando carga en otra [se acentúan cuando son graves]; y $3^{\circ}$ cuando las combinaciones capaces de formar diptongo ó triptongo se disuelven cargándose la pronunciación en la vocal débil, ésta deberá siempre llevar el signo gráfico [se acentúan cuando presentan hiato con vocal cerrada tónica] (MV1).

Las esdrújulas se acentuaban todas, sin excepción.

Esta propuesta era para Martínez Vigil "más fácil y, por consiguiente, mejor" (MV1). "obedece a un plan filosófico y relativamente sencillo, a diferencia del antiguo sistema acentual de la Academia [que diferenciaba como vimos según el tipo de palabra de que se tratase] -muy semejante al actual chileno- que no obedece a ningún plan" (MV1). Según este autor, "Falta en [el sistema chileno] belleza, porque no tiene plan; unidad, porque no tiene reglas fijas, y exactitud y verdad, porque carece de harmonía" (MV1). 
En la propuesta sobre tildación usada en Chile también se acentuaban todas las palabras esdrújulas. La diferencia residía en que se tildaban todas las palabras agudas terminadas en vocal y todas las graves terminadas en consonante, sin excepción. Sobre esta regla señalaba Del Solar: "en Chile [...] proclamamos el principio de que "la regla que es pareja no es dura": toda palabra grave terminada en vocal no lleva acento i toda la que termine en consonante lo lleva: no tenemos en nuestra Constitucion castas privilejiadas. Nuestras reglas, pues, son invariables i obedecen a un plan fijo, i nó, como lo dice $\mathrm{Vd}$., que no obedecen a ninguno" (DS2).

Para Del Solar la regla académica de acentuar las voces graves terminadas en consonante salvo que se tratara de $n$ o $s$, y las agudas terminadas en vocal, $n$ y $s$ asignaba un estatus especial ("sangre real") a estas dos consonantes, y por lo tanto, no era una regla general y por ello tampoco clara ni sencilla:

Tenemos, pues, que aquellas voces agudas que sean de sangre real (es decir con $n$ o $s$ ) pueden cargar las armas para ayudar a su patria en sus merodeos por el campo castellano. Lo contrario sucede si estas dicciones de real estirpe se convierten en tan llanas que rayen ya en bonachonas, por cuya razón se las castiga con no llevar ni un palo de escoba. No importa que pidan acento a gritos virgen, volumen, adoras, martes: son llanas con $n$ i $s$ final, i por lo tanto nacieron con el pecado original, i quedan sin bautismo (DS2).

Hé aquí la gran filosofía de las reglas académicas. I ¿saben Vds., señores, lo que dicen por ahí? ¿la gran razón que dan para que a estas pobres letras 
se las considere como no existentes para los efectos de la acentuación? Que las letras escomulgadas son frecuentemente finales de tiempos de verbos, como amaran, amaras. I ¿qué tienen que ver las demas palabras terminadas en $n$ o $s$ que no son verbos, con las que lo son? (DS2).

Con su oposición a las normas sobre tildación de la RAE Del Solar manifestaba su rechazo a la Iglesia y a la nobleza, que además asociaba al statu quo español.

Para el autor, la regla académica respecto al uso del tilde en palabras graves y agudas introducía una excepción y por lo tanto la desaconsejaba:

Soi enemigo acérrimo de las escepciones; cuando se da una regla, debe, a mi juicio, seguirse en todo caso. ¿Por qué ha de quitarse en acento a órden i a Cárlos, que por la regla de graves terminadas en consonante tiene derecho a llevar, i ha de colgársele a pasion i a Jesus, que son agudos terminados en consonante? I repito a $\mathrm{Vd}$. que no admito la teoría de las reservas mentales para los vocablos terminados en $n$ o $s$, ménos aun por dimanar esas reglas académicas de escepciones a otras reglas (DS3).

Para Martínez Vigial, en cambio, lo que constituía una excepción era el tilde diferencial que proponía la ortografía chilena para distinguir algunas formas verbales (que de acuerdo a la regla general chilena no debían llevar tilde porque eran palabras agudas terminadas en vocal). Sobre esta regla (la número 12 de Bello) opinaba Del Solar:

Volviendo a nuestros debatidos acentos, diré que la regla $12^{\mathrm{a}}$. de Bello para acentuar las segundas personas del singular de los verbos es una regla 
diferencial mui importante para no confundir estás, presente del indicativo del verbo estar, con estas, adjetivo femenino plural, que no lleva acento en ninguno de los dos sistemas; amarás, futuro de indicativo, con amaras, pretérito del subjuntivo, que tampoco lleva acento en ningun sistema (DS3).

Para Martínez Vigil, como se ha mencionado ya, esta norma chilena introducía una serie de excepciones a la norma general que volvían compleja la ortografía y le quitaban fijeza:

El sistema seguido por Bello en sus reglas $6^{\mathrm{a}}$., $9^{\mathrm{a}}$., $13^{\mathrm{a}}$. y $15^{\mathrm{a}}$. es, como sistema, de lo peor que puede idearse en materia de acentuación ortográfica. Ordenar acentuar las palabras sin más razón que la conveniencia de distinguirlas de otras, es un criterio que sólo puede ser admisible en el único caso de faltarnos reglas precisas, y que demuestra acabadamente la falta de fijeza y la complejidad de las adoptadas. Y acentuar régimen, céfiro, márgenes, démosle, no precisamente por ser voces esdrújulas, sino porque la vocal en que carga el acento en la primera, régimen, no es la última de la dicción; porque de no hacerlo, debería suponerse acentuada en la segunda, céfiro, la penúltima vocal; por ser plural la tercera; y la última por ser compuesto de enclítico, es complicar inútilmente una materia de suyo sencilla y recargar la memoria con preceptos tan engorrosos como innecesarios (MV3).

Recordemos que de todos modos la "ortografía académica" también proponía reglas diferenciales, aunque de menor extensión y mayor comprensión (ver 4.2.). 
En última instancia discutían los conceptos de excepción y de generalidad. Para Del Solar la regla académica que acentuaba las palabras graves terminadas en consonante, salvo $n$ y $s$, y las agudas terminadas en vocal, $n$ y $s$, constituían una excepción a la norma general de acentuación y por tanto no era racional, general, ni sencilla.

Para Martínez Vigil, en cambio, esta norma era más racional, más general, y por ello más sencilla, porque seguía un principio general de acentuación de palabras obviando la categoría gramatical (como sí tenía en cuenta la academia con anterioridad) o el número de sílabas de la palabra (como la formulación de Bello). Para Martínez Vigil, la formulación de las reglas de la propuesta chilena era más compleja y dificultaba la comprensión y generalización de la norma (y en consecuencia no era clara ni sencilla), porque se apelaba a la cantidad de sílabas que componían la palabra.

Del Solar reconocía que la formulación de las normas chilenas de acentuación eran complejas, señalando que existía un "sistema analítico de acentuación" (el que trascribió en su segunda carta a la RNLCS) y un "sistema elemental", que era el usado para enseñar la tildación en las escuelas chilenas:

Mucho hincapié hace $\mathrm{Vd}$. en las numerosas reglas que da don Andres Bello para la acentuacion de las palabras, segun el número de sílabas. En ello no encuentro yo mas que una comodidad para esclarecer el sistema ortográfico i de ninguna manera para oscurecerlo i hacerlo mas difuso. Este sistema analítico de acentuacion, mui bueno para servir de norma a las personas que se dedican a las obras didácticas, no fue seguido por el señor Várgas Fontecilla en su testo, inspirado por las doctrinas de Bello i patrocinado por él 
como propio, porque no lo consideró necesario; bastaba el sintético para la enseñanza elemental, i fue éste el que adoptó. Ya he dicho a Vd. que solo se reducen a cinco todas nuestras reglas: $1^{\mathrm{a}}$. Agudas terminadas en vocal, 2a . Agudas terminadas en consonante, $3^{\mathrm{a}}$. Graves terminadas en vocal, $4^{\mathrm{a}}$. Graves terminadas en consonante, $5^{\mathrm{a}}$. Esdrújulas (DS3).

A esta complejidad Martínez Vigil sumaba las reglas diferenciales para distinguir algunos verbos, con las que como se ha señalado, tampoco estaba de acuerdo.

\section{Las posiciones político- lingüísticas}

Los discursos sobre la acentuación de las figuras estudiadas exponen las diferencias de opinión sobre la unidad del español de los dos autores. Martínez Vigil era partidario de la unidad linguiística de las regiones hispanohablantes y asignaba a la Real Academia Española (RAE) un rol destacado para su mantenimiento. Del Solar negaba legitimidad a la institución normativa y rechazaba toda propuesta que de ella proviniera.

Del Solar destacaba la posición conservadora de la RAE, en el entendido de que el conservadurismo político redundaba para el autor en conservadurismo linguiístico. Cuestionaba que la Academia solo aceptara en los hechos reformas que provinieran de ella misma, aunque en sus discursos enunciara lo contrario:

Piensa Vd. que la Academia española ha dado un gran paso en el progreso con la reforma de la acentuación; yo opino todo lo contrario. La Academia no será jamas reformista miéntras no modifique sus estatutos, por los cuales no se da el 
título de académico al que lo merece sino al que presenta una solicitud para aspirar a ese honor; miéntras no se despoje de ese exclusivismo, que le es característico, no aceptando reforma alguna que no proceda de su seno, aunque afirme en el prólogo de su Diccionario que "no desoirá ningún consejo, venga de donde viniere, ni dejará de acatar la buena intención, aunque no la recomiende el acierto (DS2).

En relación con el vínculo entre la Academia y los países hispanoamericanos, Del Solar consideraba que se trataba de una relación colonial, en que los países americanos actuaban con total servilismo, salvo Chile. Señalaba, por ejemplo, a propósito de la acentuación de los nombres extranjeros:

I ¿dónde deja Vd. [refiriéndose a MV] la regla en que se manda acentuar "los términos latinos y los nombres propios estranjeros con sujecion a las reglas que se han prescrito para las dicciones castellanas; v. g.: ítem, memorándum, exequátur, tránseat, Schleger, Winckelmann, Tolón, Leicéster, Windsor, Amiéns, Schúberl”. (DS2) ¿Quién le ha dicho a nuestra venerable abuela que debe inmiscuirse en ordenar acentos en tienda ajena? Eso queda para sus pacientes colonias, que soportan todas sus chocheces, si bien Chile no le ha salido tan suave en la lana (DS2).

Martínez Vigil, por el contrario, estimaba que Del Solar (y otros escritores) tenían una actitud política demasiado independiente en relación con la Academia y que a esto fundamentalmente respondía su desacuerdo con las normas académicas. Señalaba que sus diferencias con las propuestas de la RAE no se debían tanto a diferencias de 
concepción teórica en cuanto a la ortografía, sino a diferencias políticas, al interés de desmarcarse de España: "No me he podido persuadir a que Vd. y otros escritores competentes opinen de distinto modo, sino influidos por cierto espíritu de exagerada independencia, que mira con desdeñosa prevención cuanto procede de España, y que, siguiendo las huellas de Gutiérrez y Sarmiento, no considera democrática ni viril someterse en materia de lenguaje a las decisiones superiores de una Corporación española" (MV3). Martínez Vigil reconocía la autoridad de la institución normativa y por ello consideraba que su función debía ser la de establecer criterios normativos sobre el lenguaje para toda la comunidad hispanohablante a partir de la ponderación de las diferencias en su uso: "es indiscutible la conveniencia de una Corporación que haga de juez en este pleito ruidoso en que nos vemos metidos cuantos hablamos o pretendemos hablar en lengua castellana, y decida con criterio sereno las divergencias del uso, árbitro, juez y norma del lenguaje, según el poeta latino" (MV3).

La Academia tenía de todos modos un límite en su accionar: el propio uso y la "opinión de autores"; es decir, si sus normas no estaban de acuerdo con la "práctica general" no debían seguirse:

Y este poder, delegado en la Academia Española por lo que a nuestro idioma se refiere, tiene, en sí mismo y en su naturaleza, demarcado el límite hasta que debe llegar. La Academia obra dentro de sus atribuciones legítimas en tanto respeta este linde y limita su papel al de simple juez, encargado de dirimir las contiendas que se suscitan: traspasa este límite, y se excede consiguientemente en sus facultades, cuando sus fallos no sancionan una práctica general, y sustituye la opinión de los autores con su 
particular opinión y con sus resoluciones sin alzada las en último resultado decisiones supremas del uso (MV3).

Para defender su postura cada autor apeló a la opinión de otras figuras de prestigio. Del Solar trascribió la propuesta sobre acentuación de Andrés Bello publicada en los Anales de la Universidad de Chile en 1845, y se respaldó en la autoridad del reconocido cientista del lenguaje naturalizado chileno Rodolfo Lenz, en particular su obra De la ortografía castellana, publicada también en los Anales de Universidad de Chile, en 1894:

No veo, pues, ninguna razón, dice el doctor Lenz, sabio profesor de castellano en el Instituto Pedagójico de Santiago, para abandonar el buen uso general de Chile en favor del malo de España. Volver atrás, aceptar i prescribir para la enseñanza del Estado la ortografía irrazonable i difícil de la Real Academia Española equivaldría a la confesión de que los chilenos todavía no han llegado a la madurez e independencia intelectual, o que son muy bonachones, pues aceptan lo malo de mano ajena, donde solo tienen que guardar lo bueno de la propia (Rodolfo Lenz. De la ortografía castellana. Publicado en los Anales de la Universidad de Chile, 1894) (DS2)

En el texto citado, Lenz argumentaba fuertemente en contra de las recomendaciones ortográficas académicas (a la que calificaba de "irrazonable i difícil") apelando a la "madurez e independencia intelectual" de los chilenos. La ortografía chilena daba cuenta de la madurez de Chile y de su independencia, no solo política sino también ideológica.

Martínez Vigil por su parte apeló a la propia Academia (gramáticas de 1880 y 1883), al gramático español Eduardo 
Benot (Prosodia castellana, de $1866^{9}$ ) y al filólogo venezolano Baldomero Rivodó (Entretenimientos gramaticales $^{10}$, de 1872). Tanto el autor peninsular como el americano, señalaba Martínez Vigil, destacaban (como él mismo) la sencillez de la propuesta académica en cuanto a la tildación de palabras terminadas en $s$ y $n$ :

Escritores de gran cuenta la recogieron, y aumentaron el número de puntos que había necesidad de reformar, como Benot en 1866, y Rivodó en 1872; y la Academia española, en la edición de 1880 de su Gramática, trajo la trascendental reforma de que aquellas letras $[n$ y $s$ finales] no se consideraban escritas (MV2).

Un distinguido escritor americano, don Baldomero Rivodó, a quien sin palmar injusticia no podría tildarse de afecto a la Academia, dice tratando de este punto, por lo que respecta a las voces terminadas en $s$, en su obra Entretenimientos gramaticales: "Esta innovación es conveniente, sin duda. Ella había sido propuesta y se venía siguiendo hace ya algún tiempo por muchos escritores; pues tal práctica, aunque se opone a lo natural, tiene en su abono la ventaja de que simplifica en gran manera las reglas de acentuación" (MV2).

Otro autor afamado, el eminente ortólogo español don Eduardo Benot, sienta en su magistral

\footnotetext{
9 Parece haber una confusión en cuanto a los títulos y los años de publicación de las obras de Benot: Prosodia castellana y versificación es del año 1892, y Examen crítico de la acentuación castellana es de 1866.

${ }^{10}$ El nombre completo es Entretenimientos gramaticales: colección de tratados y opúsculos sobre diferentes puntos relativos al idioma castellano.
} 
Prosodia Castellana que "el precepto académico de no considerar nunca como escritas ni la $n$ ni la $s$ para los efectos ortográficos, es de una sencillez tan grande, que no debe titubearse en admitirlo" (MV2).

El argumento para asignar a la $n$ un estatus particular y en consecuencia no considerarla como escrita a los efectos ortográficos se asentaba en la consideración de que esta consonante es marca de plural en los verbos y por lo tanto "no puede ser considerada como consonante formativa de vocablo, sino meramente como signo de plural" (MV3). En cuanto a la $s$, solo se recordaba el precepto académico de "no considerarla como escrita" a los efectos ortográficos.

Los autores citados dan cuenta de los nombres que eran referencia teórica sobre la temática para cada uno de las figuras estudiadas. También muestra la circulación de las obras y los autores más difundidos en Chile y Uruguay. La indiscutible incidencia de la obra y el trabajo de Lenz (reciente catedrático -desde 1895- de Linguística Castellana en la Universidad de Chile en la época en que se desarrollaba la polémica que nos ocupa) en los intelectuales de aquel país ha sido estudiada por ejemplo por Rabanales. Zamorano y Montoro del Arco y Zamorano por su parte han señalado la importante influencia de la teoría gramatical de Benot (curiosamente de escaso arraigo en España) en Uruguay entre los años 20 a 40 del siglo XX. La referencia de Martínez Vigil a Benot a fines del siglo XIX permite reconocer que la incidencia del autor es anterior, al menos en cuestiones ortográficas. 


\section{Consideraciones finales}

La polémica sobre acentuación ortográfica entre Fidelis Del Solar y Carlos Martínez Vigil, centrada en la tildación de palabras graves y agudas terminadas en $n$ y $s$ permitió observar que, independientemente de las normas de acentuación que cada uno defendía, ambos compartían la representación sobre cuáles eran los principios que debían regirlas. La discusión sobre la tildación de palabras agudas y graves terminadas en $n$ y $s$ los llevó a problematizar los conceptos de excepción y de generalidad, que ambos autores destacaban como rasgos que toda buena ortografía debía tener (aunque luego tuvieran posiciones contrarias respecto a cuáles eran las normas que introducían excepciones, si las académicas o las chilenas).

La cuestión de la excepcionalidad se volvió tema central de la polémica porque tanto Del Solar como Martínez Vigil entendían que atentaba contra los principios de racionalidad, claridad y sencillez que (de acuerdo a la concepción iluminista imperante, como he señalado) ambos creían que debían regir toda norma ortográfica, y en particular las normas de acentuación. La introducción de excepciones a reglas de cierta generalidad le quitaba sencillez, claridad y racionalidad a la norma ortográfica. La puesta en práctica de estos tres principios otorgaba utilidad a la normativa, que en última instancia era el fin que debía perseguir toda modificación ortográfica: servir de guía para la escritura.

Por otra parte, el debate da cuenta del modo en que cada autor proponía resolver el vínculo de Hispanoamérica con España, manifestado en su posición sobre la unidad del español. Mientras que Martínez Vigil proponía la conservación del lazo lingüístico con España y aceptaba la función tutelar de la RAE para la conservación de la unidad del español, Del Solar defendía la independencia lingüística 
de Hispanoamérica, evidenciada en la existencia de una ortografía divergente a la académica como lo era la ortografía chilena.

\section{Bibliografia}

Área, Lelia, Liliana Pérez y Patricia Rogieri .'Dos casos en la constitución de la lengua como objeto de reflexión intelectual en el siglo XIX americano: SarmientoBello”. Políticas lingüísticas para América Latina. Vol II. Comps. Roberto Bein, Nidia Blaisten y Lía Varela. Buenos Aires: Eudeba, 1999. 47-58.Impreso.

Arnoux, Elvira. Los discursos sobre la nación y el lenguaje en la formación del Estado (Chile, 1842-1862). Estudio glotopolítico. Buenos Aires: Santiago Arcos Editor, 2008. Impreso.

--------. y José Del Valle. "Las representaciones ideológicas del lenguaje: Discurso glotopolítico y panhispanismo". Spanish in Context 7, 1 (2010): 124. Impreso.

Blommaert, Jan. "The debate is open". Language Ideological Debates. Ed. Jan Blommaert. Berlín-Nueva York: Mouton de Gruyter, 1999. 1- 38. Impreso.

Boyer Henry. De l'autre côté du discours. Recherches sur le fonctionnement des représentations communautaires. Paris: L'Harmattan, 2003. Impreso.

Calvet, Louis Jean. Las políticas lingüísticas. Buenos Aires: Edicial, 1996. Impreso.

Gómez Asencio, José. "El trabajo de la Real Academia Española en el siglo XVIII (y después)". Península. Revista de Estudios Ibéricos 5 (2008): 31-53. Impreso.

Figueroa, Pedro Pablo. Diccionario biográfico de Chile. Santiago de Chile: Imprenta, Litografía i Encuadernacion Barcelona, 1901. Impreso. 
Halperin Donghi, Tullio. Letrados y pensadores. El perfilamiento del intelectual hispanoamericano en el siglo XIX. Buenos Aires: Emecé, 2013. Impreso.

Jernudd, Björn y Jyotirindra Das Gupta. "Towards a Theory of Language Planning". Can Language be Planned? Eds. Joan Rubin y Björn Jernudd. Honolulú: EastWest Center Press, 1971. 195- 215. Impreso.

Jodelet, Denise. "La representación social: fenómenos, concepto y teoría". Psicología social. Editorial Serge Moscovici. Barcelona: Paidós, 1993. 469- 494. Impreso.

Martínez de Sousa, José. "La obra académica a lo largo de tres siglos". El dardo en la Academia: Esencia y vigencia de las academias de la lengua española. Vol. I. Eds. Silvia Senz y Montserrat Alberde. Barcelona: Melusina, 2011. 621- 690. Impreso.

Martínez Vigil, Carlos. Polémica sobre acentuación ortográfica con Don Fidelis P. del Solar. Montevideo: Imprenta Gaceta Comercial, 1941. Impreso.

Montero Bustamante, Raúl. "Iniciación del Uruguay en el modernismo literario". Homenaje a Don Raúl Montero Bustamante. Selección de sus escritos literarios e históricos. T.II. Montevideo: Instituto Histórico y Geográfico del Uruguay- Academia Nacional de Letras, 1955. 6- 62.Impreso.

Montoro del Arco, Esteban y Alfonso Zamorano Aguilar. "Notas sobre teoría sintáctica y fraseológica en manuales uruguayos de gramática escolar". Ars longa, diez años de AJIHLE. Vol. II. Comps. María Teresa Encimas Manterola, Mónica González Manzano, Miguel Gutiérrez Maté, María A. López Vallejo, Carolina Martín Gallego, Laura Romero Aguilera, Marta Torres Martínez e Irene Vicente Miguel. Buenos Aires: Voces del Sur, 2010. 739- 756. Impreso. 
Niño-Murcia, Mercedes. "Ideología lingüística hispanoamericana en el siglo XIX: Chile (18401880)". Hispanic Linguistics 9, 1 (1997): 100142.Impreso.

Oroño, Mariela. "Las representaciones sociolingüísticas en José Pedro Varela y Juan Zorrilla de San Martín: primera aproximación". Revista Digital de Políticas Lingüísticas de la AUGM 7 (2015): 26- 50.Impreso.

Pérez Petit, Víctor. Rodó. Su vida, su obra. Montevideo: Imprenta Latina, 1918.Impreso.

Rojas, Dario y Tania Avilés. "La recepción de Voces usadas en Chile (1900) de Aníbal Echeverría y Reyes entre sus contemporáneos". Boletín de Filología XLVII, 2 (2012): 149- 175. Impreso.

Rabanales, Ambrosio. "Rodolfo Lenz". Onomazein 7 (2002): 161- 181. Impreso.

Rosenblat, Ángel. "Las ideas ortográficas de Bello". Obras completas de Andrés Bello. Vol. V, eds. Rafael Caldera, Pedro Grases, Augusto Mijares, Enrique Planchart y Julio Planchart. Caracas: Fundación de La Casa de Bello, 1981. IX- CXXXVIII. Impreso.

Solar, Fidelis del. Carta de par en par: Comunicación dirijida a Montevideo para la revista Nacional de Literatura y Ciencias Sociales, inédita en ese periódico por haber cerrado su publicación. Santiago de Chile: Imprenta, Litografía i Encuadernacion Barcelona, 1898. Impreso.

Zamorano Aguilar, Alfonso. "Historia de la gramática española en América (ii). Uruguay. Los manuales escolares de R. Abadíe Soriano y H. Zarrilli (1924, 1937)". Educo. Revista de Investigación Educativa 3 (2008): 71-100. Impreso. 